\title{
Erratum zu: Kostenloser ÖPNV: Akzeptanz in der Bevölkerung und mögliche Auswirkungen auf das Mobilitätsverhalten
}

\section{Mark A. Andor · Lukas Fink • Manuel Frondel • Andreas Gerster • Marco Horvath}

Online publiziert: 29. Januar 2021

(C) List-Gesellschaft e.V. 2021
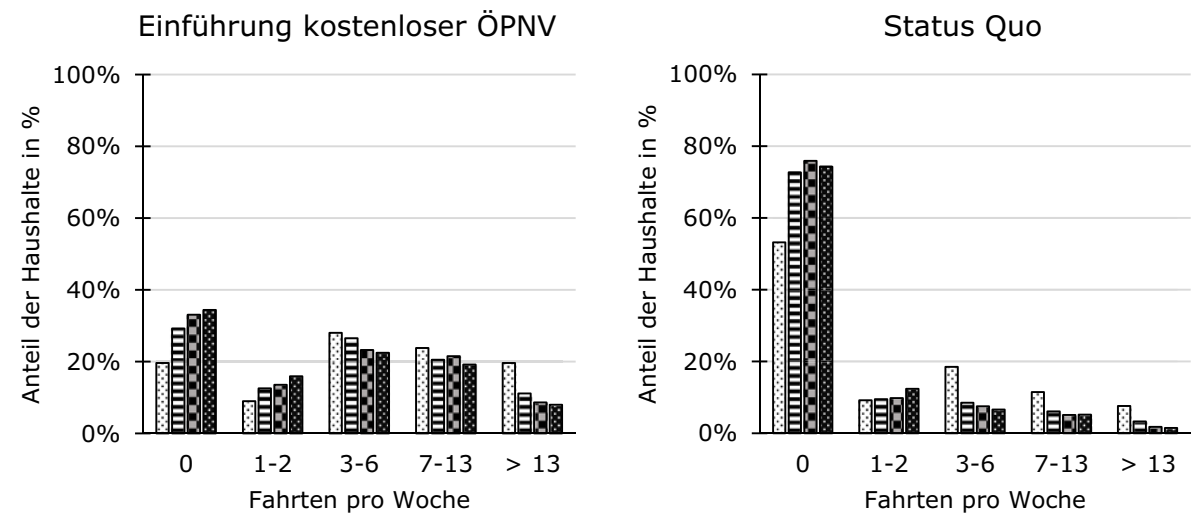

๒geringes Einkommen घmittleres Einkommen

Whohes Einkommen sehr hohes Einkommen

Abb. 4 Derzeitige Anzahl der ÖPNV-Fahrten pro Woche und nach Einführung eines kostenlosen ÖPNV nach Einkommensgruppen

Die Online-Version des Originalartikels ist unter https://doi.org/10.1007/s41025-020-00207-y zu finden.

M. A. Andor $(\bowtie) \cdot$ L. Fink $\cdot$ M. Frondel $\cdot$ M. Horvath

RWI - Leibniz-Institut für Wirtschaftsforschung, Essen, Deutschland

E-Mail: andor@rwi-essen.de

M. Frondel

Ruhr-Universität Bochum, Bochum, Deutschland

A. Gerster

Universität Mannheim, Mannheim, Deutschland 


\section{Erratum zu:}

\section{List Forum 2020}

https://doi.org/10.1007/s41025-020-00207-y

Leider kam es im Produktionsprozess zu einem Fehler und es wurde dadurch eine fehlerhafte Version der Abb. 4 veröffentlicht. Die Achsenbeschriftung und Legende waren nicht korrekt. Die korrigierte Abb. 4 ist hier dargestellt.

Der Originalbeitrag wurde korrigiert. 